\title{
Peningkatan Pembelajaran Cara Hidup Bersih dan Sehat (PHBS) dengan Penyuluhan Kesehatan Gigi dan Cuci Tangan
}

\author{
Ana Setyowati ${ }^{1}$, Swasti Artanti ${ }^{2}$, Ida Baroroh ${ }^{3}$, Ivan Chabibillah ${ }^{4}$ \\ Email: anena.nenaza@gmail.com \\ Akademi Kebidanan Harapan Ibu Pekalongan \\ Jl. Sriwijaya No. 7 Pekalongan \\ Telp/Fax (0285) 4416108
}

\begin{abstract}
Abstrak
Derajat kesehatan merupakan salah satu unsur penting dalam upaya peningkatan Indeks Pembangunan Manusia (IPM) bangsa Indonesia. Sementara itu, derajat kesehatan tidak hanya ditentukan oleh pelayanan kesehatan, tetapi yang lebih dominan justru adalah kondisi lingkungan dan perilaku masyarakat. Upaya untuk mengubah perilaku masyarakat agar mendukung peningkatan derajat kesehatan dilakukan melalui program pembinaan Perilaku Hidup Bersih dan Sehat (PHBS). Tujuan pengabdian masyarakat ini adalah memberikan penyuluhan kesehatan gigi dan cuci tangan. Metode pedidikan kesehatan yang dilakukan yaitu metode persiapan kegiatan, tahapan pelaksanaan kegiatan yaitu (1) Sosialisasi dan Perijinan, (2) Melakukan Affirmasi dan Pre Test (3) Melakukan penyuluhan kesehatan gigi dan cuci tangan. (4) Evaluasi hasil kegiatan pendidikan kesehatan dengan Post Test. Hasil kegiatan penyuluhan yaitu terdapat peningkatan pemahaman dan pengetahuan tentang pentingnya Perilaku Hidup Bersih dan Sehat terutama tentang Kesehatan Gigi dan Cuci Tangan.
\end{abstract}

Kata kunci: Penyuluhan, Kesehatan Gigi, Cuci tangan.

\begin{abstract}
Health status is one of the important elements in efforts to improve the Indonesian Human Development Index (HDI). Meanwhile, the degree of health is not only determined by health services, but what is more dominant is the environmental conditions and people's behavior. Efforts to change people's behavior in order to support the improvement of health status are carried out through the Clean and Healthy Behavior (PHBS) development program. The aim of community service is to provide dental health education and hand washing. The method of health education carried out is the method of preparation of activities, the stages of implementation of activities, namely (1) Socialization and Licensing, (2) Conducting Affirmations and Pre Tests (3) Conducting dental health education and hand washing. (4) Evaluate the results of health education activities with the Post Test. The results of counseling activities that there is an increase in understanding and knowledge about the importance of Clean and Healthy Behavior, especially about Dental Health and Hand Washing.
\end{abstract}

Keywords: Counseling, Dental Health, Hand washing.

\section{Pendahuluan}

Derajat kesehatan merupakan salah satu unsur penting dalam upaya peningkatan Indeks Pembangunan Manusia (IPM) bangsa Indonesia. Sementara itu, derajat kesehatan tidak hanya ditentukan oleh pelayanan kesehatan, tetapi yang lebih dominan justru adalah kondisi lingkungan dan perilaku masyarakat. Upaya untuk mnegubah perilaku masyarakat agar mendukung peningkatan derajat kesehatan dilakukan melalui program pembinaan Perilaku Hidup Bersih dan Sehat (PHBS) ${ }^{(1)}$.

Perilaku Hidup Bersih dan Sehat atau biasa disingkat dengan PHBS yakni semua perilaku kesehatan yang dilakukan karena kesadaran pribadi sehingga keluarga dan seluruh anggotanya mampu menolong diri sendiri pada bidang 
kesehatan serta memiliki peran aktif dalam aktivitas masyarakat ${ }^{(2)}$. Perilaku hidup bersih sehat pada dasarnya merupakan sebuah upaya untuk menularkan pengalaman mengenai pola hidup sehat melalui individu, kelompok ataupun masyarakat luas dengan jalur - jalur komunikasi sebagai media berbagi informasi. Ada berbagai informasi yang dapat dibagikan seperti materi edukasi guna menambah pengetahuan serta meningkatkan sikap dan perilaku terkait cara hidup yang bersih dan sehat ${ }^{(2)}$.

Adapun langkah-langkah yang berupa edukasi melalui pendekatan masyarakat, pembinaan suasana dan pemberdayaan masyarakat yang tujuanya agar masyarakat mampu mengenal dan mengetahui masalah kesehatan yang ada disekitar, terutama pada tingkatan rumah tangga sebagai awal untuk memperbaiki pola dan gaya hidup agar lebih sehat ${ }^{(2)}$.

Tujuan utama dari gerakan PHBS adalah meningkatkan kualitas kesehatan melalui proses penyadartahuan yang menjadi awal dari kontribusi individu - individu dalam menjalani perilaku kehidupan sehari - hari yang bersih dan sehat. Manfaat PHBS yang paling utama adalah terciptanya masyarakat yang sadar kesehatan dan memiliki bekal pengetahuan dan kesadaran untuk menjalani perilaku hidup yang menjaga kebersihan dan memenuhi standar kesehatan.

Salah satu indikator perilaku hidup bersih dan sehat yag belum berjalan dengan baik didasarkan pada tingkat kematian dan kesakitan di dunia saat ini masih tinggi akibat penyakit-penyakit yang berkaitan dengan air. Sanitasi dan perilaku hidup bersih dan sehat, sepertirendahnya kebiasaan cuci tangan menggunakan sabun dan air mengalir $^{(1)}$.
Setiap rumah memiliki sabun, namun partisipasi cuci tangan pakai sabun sebelum beraktifitas amat rendah. Dalam kehidupan beragama dan kesehatan mengajarkan mencuci tangan sebelum makan, karena cuci tangan akan mengurangi penyakit diare dan saluran pernafasan akut (ISPA) yang saat ini meruapakn penyakit mematikan terutama bagi anak $^{(3)}$.

Faktor-faktor yang mempengaruhi kesehatan anak adalah nutrisi yang seimbang, olahraga teratur, istirahat yang cukup dan kebersihan diri serta lingkungannya. Anak dilatih untuk mampu mengurus dirinya sendiri sekaligus menjaga kebersihan diri, dimulai dari kegiatan yang sederhana seperti mandi, menyikat gigi dan mencuci tangan ${ }^{(4)}$.

Kesehatan gigi dan mulut merupakan salah satu faktor yang mendukung paradigma sehat dan faktor perilaku dari individu seseorang. Kesehatan tubuh secara keseluruhan banyak dipengaruhi oleh kesehatan dari gigi dan mulut itu sendiri. Jika tidak dapat menjaga kesehatan gigi dengan baik maka akan menyebabkan bakteri menyerang gigi dan menjadikan gigi berlubang ${ }^{(5)}$.

Tujuan dilakukannya pengabdian kepada masyarakat ini adalah untuk melaksanakan Tri Dharma Perguruan Tinggi Akademi Kebidanan Harapan Ibu Pekalongan yaitu pengabdian kepada masyarakat di Kelurahan Bugisan Kecamatan Pekalongan Barat Kota Pekalongan, sebagai tempat mengaplikasikan ilmu kebidanan dalam konteks kesehatan dan sebagai wadah untuk berperan serta dalam peningkatan pengetahuan dan derajat kesehatan khususnya perilaku hidup bersih dan sehat di kalangan masyarakat.

\section{Metode}

Lokasi Kegiatan Pengabdian kepada masyarakat ini dipusatkan di 
Kelurahan Bugisan, Kecamatan Pekalongan Barat Kota Pekalongan. Peserta diberikan pemahaman terlebih dahulu melalui tujuan penyampaian materi pentingnya PHBS Kesehatan Gigi dan Cuci tangan.

Pelaksanaan kegiatan Pengabdian kepada Masyarakat dilakukan dengan tahapan:

a. Tahapan persiapan kegiatan

1) Menentukan prioritas masalah berdasarkan data

2) Mempersiapkan peralatan yang dibutuhkan saat melakukan kegiatan

3) Menentukan waktu pelaksanaan dan lamanya kegiatan bersama tim kegiatan pengabdian kepada masyarakat.

b. Tahapan pelaksanaan kegiatan

1) Tempat : Bugisan Kecamatan Pekalongan Barat

2) Waktu : 8 Februari 2019

3) Pukul : 08.00 - selesai

4) Pelaksana : Dosen dan mahasiswa

5) Langkah pelaksanaan

a) Sosialisasi dan Perijinan

b) Melakukan Affirmasi dan Pre Test

c) Melakukan Pendidikan kesehatan pada anak tentang PHBS Kesehatan gigi dan Cuci tangan

d) Evaluasi hasil kegiatan dengan Post Test.

\section{Hasil dan Pembahasan}

Kegiatan Pengabdian kepada Masyarakat dengan topik "peningkatan pembelajaran cara hidup bersih dan sehat (PHBS) dengan penyuluhan kesehatan gigi dan cuci tangan di Kelurahan Bugisan Kecamatan Pekalongan Barat Kota Pekalongan" diawali dengan survey tempat dan persiapan lembar observasi yang akan dipakai pada saat pengabdian dilaksanakan.
Pengabdian

kepada masyarakat ini dilaksanakan dalam rangka sosialisasi perilaku hidup bersih dan sehat di masyarakat Kelurahan Bugisan yaitu mencuci tangan dengan air mengalir menggunakan sabun dan kesehatan gigi.

Pelaksanaan kegiatan penyuluhan kesehatan ini dilakukan untuk dapat meningkatkan pengetahuan dan kesadaran masyarakat tentang pola hidup bersih dan sehat. Pelaksanaan dala kegiatan ini berupa implementasi program kegiatan yang dilakukan yaitu penyuluhan kesehatan gigi dengan cara gosok gigi yang benar dan cara cuci tangan dengan air mengalir menggunakan sabun.

Peserta kegiatan pengabdian kepada masyarakat ini menunjukkan antusiasme yang tinggi selama kegiatan penyuluhan kesehatan dilakukan. Antusiasme tersebut ditunjukkan dengan respon peserta yang sangat baik dalam menerima materi mengenai penyuluhan kesehatan gigi dan cuci tangan yang benar.

Antusiasme masyarakat tersebut diharapkan dapat meningkatkan pemahaman tentang pentingnya Perilaku Hidup Bersih dan Sehat terutama tentang Kesehatan Gigi dan Cuci Tangan. Hal ini ditunjukkan dengan adanya perubahan pengetahuan dan pemahaman PHBS Kesehatan gigi dan cuci tangan dari hasil pre test dan post test. Hasil Post test mayoritas peserta dapat menjawab dengan benar. prosentase hasil pre test dan post test dapat dilihat pada grafik 1.1 dan 1.2 sebagai berikut. 
Grafik 1.1 Hasil Pre Test dan Post Test Kesehatan Gigi

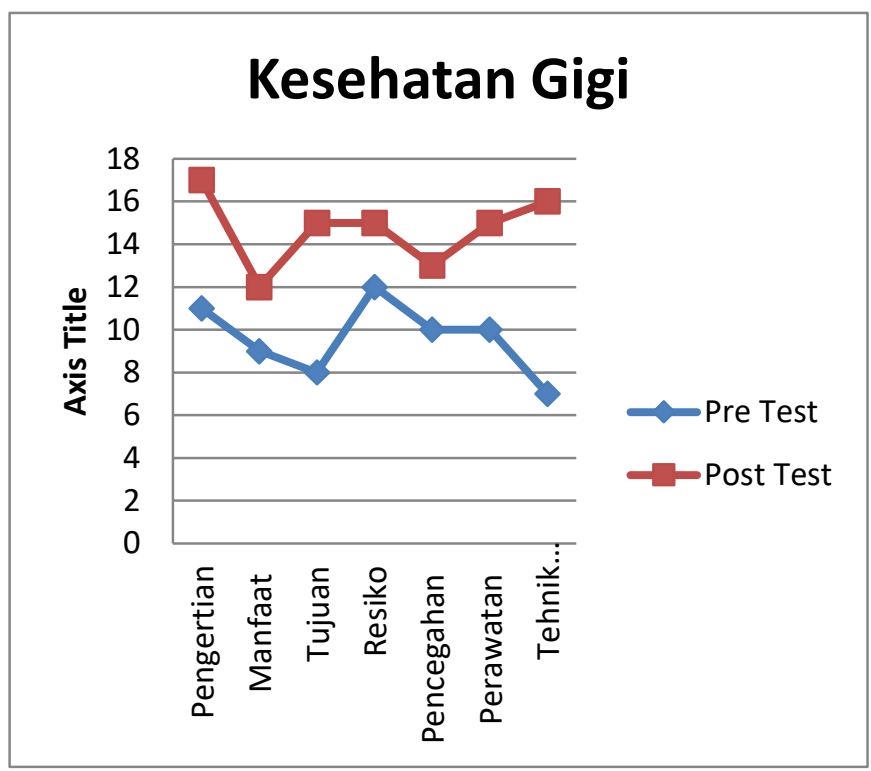

Grafik 1.2 Hasil Pre Test dan Post Test Cuci Tangan

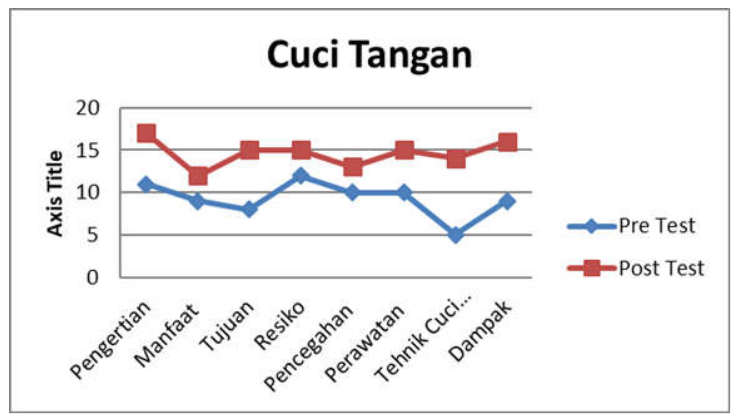

\section{Kesimpulan}

Kegiatan pengabdian kepada masyarakat dengan tema peningkatan pembelajaran cara hidup bersih dan sehat (PHBS) dengan penyuluhan kesehatan gigi dan cuci tangan di Kelurahan Bugisan Kecamatan Pekalongan Barat Kota Pekalongan dapat berjalan dengan lancar dan diterima dengan baik. Semua masyarakat Kelurahan Bugisan antusias mengikuti kegiatan penyuluhan ini. Program penyuluhan semacam ini sangat penting dilakukan dalam kehidupan bermasyarakat untuk menyadarkan pentingnya perilaku hidup bersih dan sehat.

\section{Daftar Pustaka}

[1] Kemenkes RI. Pedoman Pembinaan Perilaku Hidup Bersih dan Sehat (PHBS). Kemenkes RI. 2011.

[2] Kemenkes RI. PHBS. Kemenkes RI. 2016

[3] Depkes RI. Profil Kesehatan 2007. Departemen Kesehatan RI. 2007.

[4] Anugrah \& Hendra. Permasalahan Umum Kesehatan Anak Usia Sekolah. 2007.

[5] Anitasari, Silvia \& Endang Nina Rahayu. Hubungan Frekuensi Menyikat Gigi dengan Tingkat Kebersihan ggi dan mulut siswa sekolah dasar negeri di Kecamatan Palaran Kotamadya Samarinda Privinsi Kalimantan Timur. 2014. 